\title{
Evaluation of the static frictional coefficients of Co-Cr and gold alloys for cone crown telescope denture retainer applications
}

\author{
Masahito OHIDA' ${ }^{1}$, Keita YODA 1 , Naoyuki NOMURA², Takao HANAWA² and Yoshimasa IGARASHI ${ }^{1}$ \\ ${ }^{1}$ Removable Partial Denture Prosthodontics, Department of Masticatory Functional Rehabilitation, Division of Oral Health Sciences, Graduate School \\ of Medical and Dental Sciences, Tokyo Medical and Dental University, 1-5-45 Yushima, Bunkyo-ku, Tokyo 113-8510, Japan \\ 2Institute of Biomaterials and Bioengineering, Tokyo Medical and Dental University, 2-3-10 Kandasurugadai, Chiyoda-ku, Tokyo 101-0062, Japan \\ Corresponding author, Naoyuki NOMURA; E-mail: nnomura.met@tmd.ac.jp
}

\begin{abstract}
The static frictional coefficients (SFC) of a Co-Cr and a gold alloys were evaluated for the application of a cone crown telescope system in removable prosthesis. The SFCs of the Co-Cr alloy were lower than those of the gold alloy. The SFC of the gold alloy decreased by annealing at $85^{\circ} \mathrm{C}$ in air and was restored by re-polishing, although that of the Co-Cr alloy was stable irrespective of the annealing. The XPS analysis revealed the formation of a surface oxide layer on the gold alloy after annealing. The decrease in the SFC of the gold alloy may have been caused by the formation of an oxide layer on the surface due to annealing. The relationships among such factors as the retentive force, SFC and cone crown angle indicate that the angle of the Co-Cr alloy should be lower than that of the gold alloy based on the Körber's model.
\end{abstract}

Keywords: Co-Cr alloy, Retentive force, Static frictional coefficient

\section{INTRODUCTION}

A telescopic system with a cone crown is utilized in prosthetic treatment as the retainer for removable partial dentures and removable bridges. This system has also been used with overlay denture supported by dental implants ${ }^{1-8)}$. The clinical assessment of the cone crown telescope denture is excellent because of its clinical versatility, esthetic effect, and good prognosis $^{9-11)}$. However, the expense and the heavy weight of the denture are disadvantages because the denture is constructed from gold alloys. These problems have therefore prevented the widespread use of the cone crown telescope system.

Co-Cr alloys which possess good biocompatibility, mechanical strength and a relatively low density provide an alternative to avoid these disadvantages. $\mathrm{Co}-\mathrm{Cr}$ alloys have been applied for removable partial denture appliances for a long time. In addition, the mechanical properties and the castability of $\mathrm{Co}-\mathrm{Cr}$ alloys have been improved by modifying the casting system to include investments. The alloys have been applied for both crowns and bridges. Therefore, $\mathrm{Co}-\mathrm{Cr}$ alloys are also promising materials for cone crown telescope dentures. The retentive force of the cone crown telescope system should be clarified when $\mathrm{Co}-\mathrm{Cr}$ alloys are considered for the cone crown telescope system as substitutes for gold alloys. Problems such as the collapse of cone crown telescope dentures or detachment of inner crowns may occur if the retentive force is not appropriate. In addition, abnormal occlusal force and inhomogeneous loading during the usage of the denture affect the periodontal tissue around the abutment, leading to the loss of the tooth ${ }^{12,13)}$. Therefore, the retentive force of the cone crown telescope system plays an important role in the long- term prognosis of removable partial dentures.

The retentive force of the cone crown telescope system is influenced by the contact surface pressure, cone angle and static frictional coefficient $(\mathrm{SFC})^{14)}$. This is also affected by the thickness of the outer crown, height of the inner crown and inner crown diameter on the retentive force ${ }^{15-19)}$. However, there are few reports on the SFC of gold alloys used in the cone crown telescope system at present. Therefore, the purpose of this study is to evaluate the SFC of a Co-Cr alloy and a gold alloy, and discuss the design of the cone crown telescope system containing a $\mathrm{Co}-\mathrm{Cr}$ alloy. In addition, the effects of heat treatment on the SFC of both alloys were examined.

\section{MATERIALS AND METHODS}

\section{Sample preparation}

Wirobond 280 (BEGO, Bremen, Germany) and Degulor M (DENTSPLY SANKIN, Tochigi, Japan) were used for the SFC measurements as a Co-Cr alloy and gold alloy, respectively. The chemical composition and the properties of these alloys are listed in Tables 1, 2 and 3. The density of Wirobond 280 is half that of Degulor M. The mechanical properties of Wirobond 280 are comparable to those of Degulor $\mathrm{M}$ after casting and aging treatment.

Disc- and plate-shaped specimens were prepared for the SFC measurement of each casting alloy. The size of a disc specimen was $30 \mathrm{~mm}$ in diameter and 5 $\mathrm{mm}$ in thickness. The size of the plate specimen was 36 $\mathrm{mm}$ in width, $60 \mathrm{~mm}$ in depth, and $3 \mathrm{~mm}$ in thickness.

Wirobond 280 was cast using Bellavest SH (BEGO, Bremen, Germany) and Begosol HE (BEGO, Bremen, Germany) as the investment. The mold including wax pattern was kept for 30 minutes in air. The mold was 
Table 1 Chemical composition of Wirobond 280

\begin{tabular}{lccccccc}
\hline \multirow{2}{*}{ Alloy } & \multicolumn{5}{c}{ Composition (mass \%) } \\
\cline { 2 - 7 } & Co & Cr & W & Mo & Ga & Si, Mn \\
\hline Wirobond 280 & 60.2 & 25.0 & 6.2 & 4.8 & 2.9 & - \\
\hline
\end{tabular}

*The amount of $\mathrm{Si}$ and $\mathrm{Mn}$ is not announced in the specification sheet.

Table 2 Chemical composition of Degulor M

\begin{tabular}{lcccccccc}
\hline \multirow{2}{*}{ Alloy } & \multicolumn{7}{c}{ Composition (mass \%) } \\
\cline { 2 - 8 } & $\mathrm{Au}$ & $\mathrm{Pt}$ & $\mathrm{Pd}$ & $\mathrm{Ag}$ & $\mathrm{Ir}$ & $\mathrm{Cu}$ & $\mathrm{Others}$ \\
\hline Degulor M & 70.0 & 4.4 & 2.0 & 13.5 & 0.1 & 8.8 & 1.2 \\
\hline
\end{tabular}

*A small amount of $\mathrm{Zn}$ and Sn may be contained in the alloy.

Table 3 Physical properties of Wirobond 280 and Degulor M

\begin{tabular}{lcccccc}
\hline Alloys & $\begin{array}{c}\text { Density } \\
\left(\mathrm{g} / \mathrm{cm}^{3}\right)\end{array}$ & $\begin{array}{c}\text { Melting point } \\
\left({ }^{\circ} \mathrm{C}\right)\end{array}$ & $\begin{array}{c}\text { Elongation } \\
(\%)\end{array}$ & $\begin{array}{c}\text { Yield strength } \\
(\mathrm{MPa})\end{array}$ & $\begin{array}{c}\text { UTS } \\
(\mathrm{MPa})\end{array}$ & $\begin{array}{c}\text { Vickers } \\
\text { hardness }\end{array}$ \\
\hline Wirobond 280 & 8.5 & $1,360-1,400$ & 14 & 540 & 680 & 280 \\
Degulor M & 15.7 & $900-970$ & 17 & 620 & 740 & 235 \\
\hline
\end{tabular}

heated at $900^{\circ} \mathrm{C}$ for 30 minutes in a muffle furnace. The mold was located in the casting machine after burning out the wax (Super Cascom, DENKEN, Kyoto, Japan) and heated to $1,500^{\circ} \mathrm{C}$. Wirobond 280 was cast into the mold at $1,500^{\circ} \mathrm{C}$ in an Argon atmosphere and the mold was cooled in air.

Degulor M was cast using Cristobalite PF (Shofu, Osaka, Japan) as the investment. The mold including the wax pattern was kept for 30 minutes in air. The mold was heated at $700^{\circ} \mathrm{C}$ for 30 minutes in a muffle furnace. The mold was located in the casting machine after burning out the wax (Super Cascom, DENKEN, Kyoto, Japan) and heated to $970^{\circ} \mathrm{C}$. Degulor $\mathrm{M}$ was cast into the mold at $970^{\circ} \mathrm{C}$ in $\mathrm{Ar}$ and the mold was cooled in air.

The top and bottom surfaces of plates and discs were polished to be parallel using surface grinder (PSG52EN, Okamoto Machine Tool Works, LTD, Gunma, Japan). The discs were manually buffed using the diamond paste of \#1000 grid (SP-W, Asahi Diamond Industrial Co., Ltd, Tokyo, Japan). Optical microscope images of the surface of plate and disc of the $\mathrm{Co}-\mathrm{Cr}$ and gold alloys after polishing are shown in Figure 1. Laser microscope was used for the evaluation of the surface roughness of the alloys. The surface roughness $\left(R_{\mathrm{a}}\right)$ of plate and disc of the Co-Cr alloy were $2.16 \mu \mathrm{m}$ (SD 0.26 ) and $1.14 \mu \mathrm{m}$ (SD 0.44), respectively. The surface roughness of the plate and disc of gold alloy were 2.09 $\mu \mathrm{m}$ (SD 0.17) and $1.07 \mu \mathrm{m}$ (SD 0.24), respectively. Five sets of plates and discs of both alloys were prepared for the SFC measurements.

\section{Treatment after polishing}

Some processes were applied to the plates and discs of each alloy to examine the effect of heat treatment on the SFC: the as-polished discs and plates (condition 1) were immersed in ultra pure water at room temperature for 1 week (condition 2). After the immersion, the discs and plates were annealed at $85^{\circ} \mathrm{C}$ for 30 minutes (condition 3). The annealed discs and plates surfaces were polished with water proof emery papers up to \#1000 grid using a rotating polisher machine (METASERV 2000, BUEHLER, Illinois, USA) (condition 4). The surface roughness of plate and discs of the Co-Cr alloy (condition 4) were $0.53 \mu \mathrm{m}(0.06)$ and $0.52 \mu \mathrm{m}$ (SD 0.08), respectively. The surface roughness of the plate and disc of gold alloy (condition 4) were $0.53 \mu \mathrm{m}$ (SD 0.08) and $0.58 \mu \mathrm{m}$ (SD 0.05), respectively.

\section{Evaluation of static frictional coefficient (SFC)}

The evaluation of SFC was carried out using a tensile testing machine (AUTOGRAPH, Shimadzu, Kyoto, Japan) according to ASTM D189420). Figure 2 shows the schematic drawings of SFC measurement. Disc specimen was put on the plate which was fixed on the flat table. The total weight of the disc and weight was adjusted to $200 \mathrm{~g}$. The peak load was measured at the beginning of sliding for the evaluation of SFC when the crosshead was moved at a speed of $5 \mathrm{~mm} / \mathrm{min}$. The SFC $(\mu)$ was calculated by the equation:

$$
\mu=P / W
$$

where $P$ is the peak load and the $W$ is the total weight of the disc and weight (200 g). The SFC measurements 

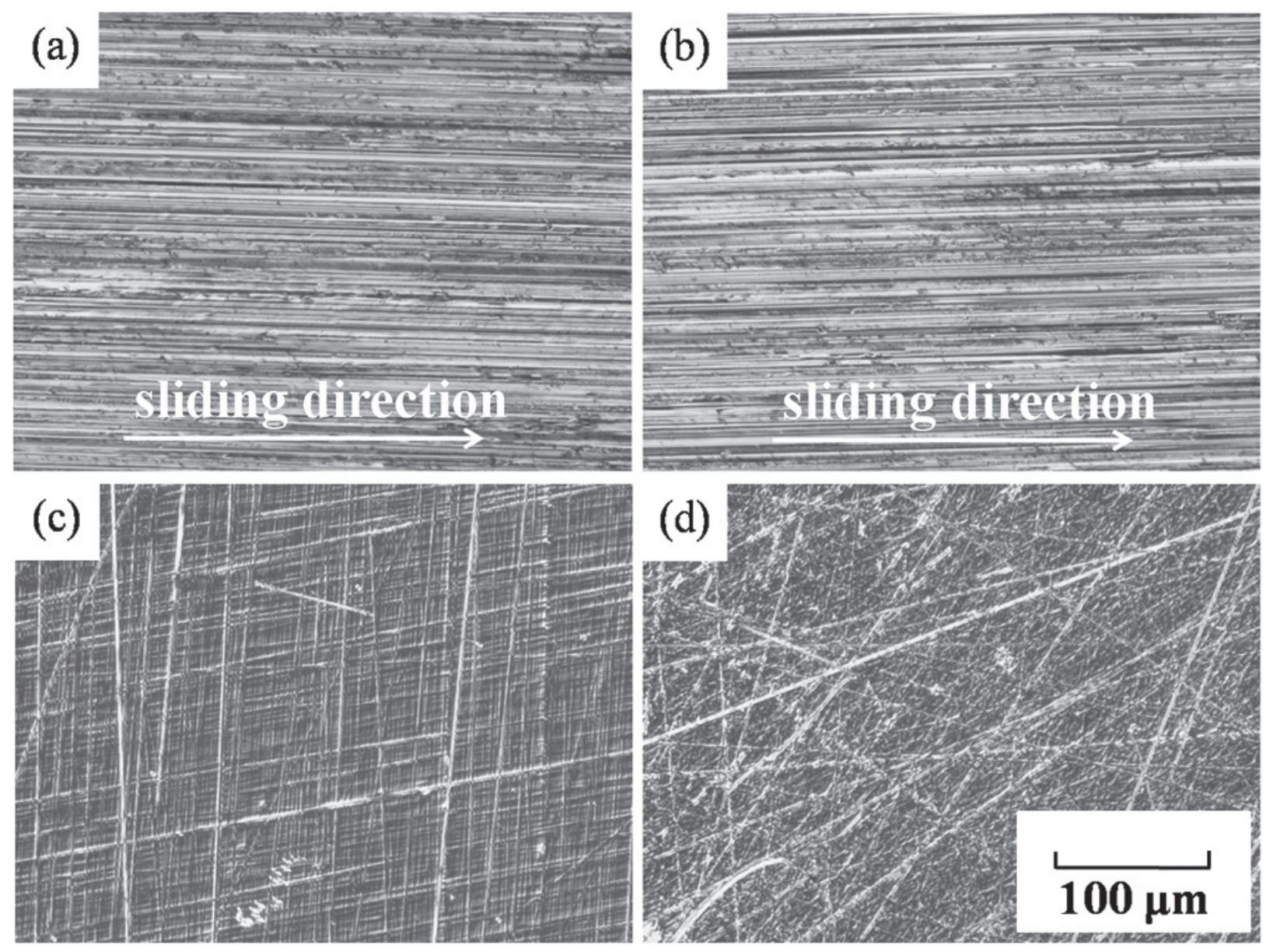

Fig. 1 Optical microscopic images of the surface of disc and plate of the Co-Cr and gold alloys after polishing. (a) Co-Cr alloy plate $\left(R_{\mathrm{a}}=2.16 \mu \mathrm{m}\right)$, (b) gold alloy plate $\left(R_{\mathrm{a}}=2.09 \mu \mathrm{m}\right)$, (c) Co-Cr alloy disc $\left(R_{\mathrm{a}}=1.14 \mu \mathrm{m}\right)$, and (d) gold alloy disc $\left(R_{\mathrm{a}}=1.07 \mu \mathrm{m}\right)$.

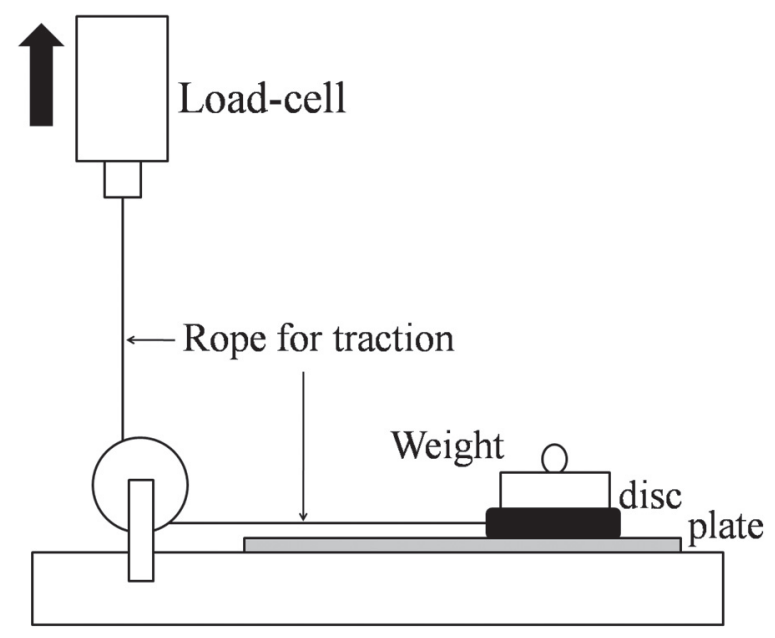

Fig. 2 Schematic drawing of SFC measurement according to ASTM D1894 (the American Society for Testing Materials) ${ }^{20)}$. were performed at $22 \pm 1^{\circ} \mathrm{C}$ and the humidity of $69 \pm 4 \%$. Five sets of disc and plate were measured five times for each alloy. The surface of the disc and plate was cleaned and dried before SFC measurement using ethanol (Wako Chemical, Miyazaki, Japan). Statistically significant differences were evaluated by the $t$-test, One-way ANOVA and Tukey's HSD method. $p<0.05$ was considered to be statistically significant.

\section{Surface analysis}

X-ray Photoelectron Spectroscopy (XPS) was performed with an electron spectrometer (JPS-9010MC, JEOL, Tokyo, Japan). All binding energies noted in this report are relative to the Fermi level and all spectra were excited with the monochromatized $\mathrm{Mg} \mathrm{K} \alpha$ line (1,253.6 $\mathrm{eV}$ ). Survey spectra were obtained over a range of 0 $1,200 \mathrm{eV}$. The binding energy was calibrated using $\mathrm{C} 1 \mathrm{~s}$ electron binding energy as $285.0 \mathrm{eV}$. The take-off angle for photoelectron detection was $90^{\circ}$ from the surface of the specimen. The chemical states of elements were determined with their binding energies ${ }^{21)}$. 


\section{RESULTS}

Static frictional coefficient of as-polished Co-Cr alloy and gold alloy

Figure 3 shows the SFC of as-polished Co-Cr alloy and gold alloy. The SFC of Co-Cr alloy is significantly lower than that of gold alloy $(t$-test, $p<0.001)$. The difference of SFC is caused by the difference of the constituent elements because the surface roughness of both alloys is almost the same.

Static frictional coefficient of Co-Cr alloy and gold alloy after various treatments

Figures 4 and 5 show the SFC of Co-Cr alloy and gold

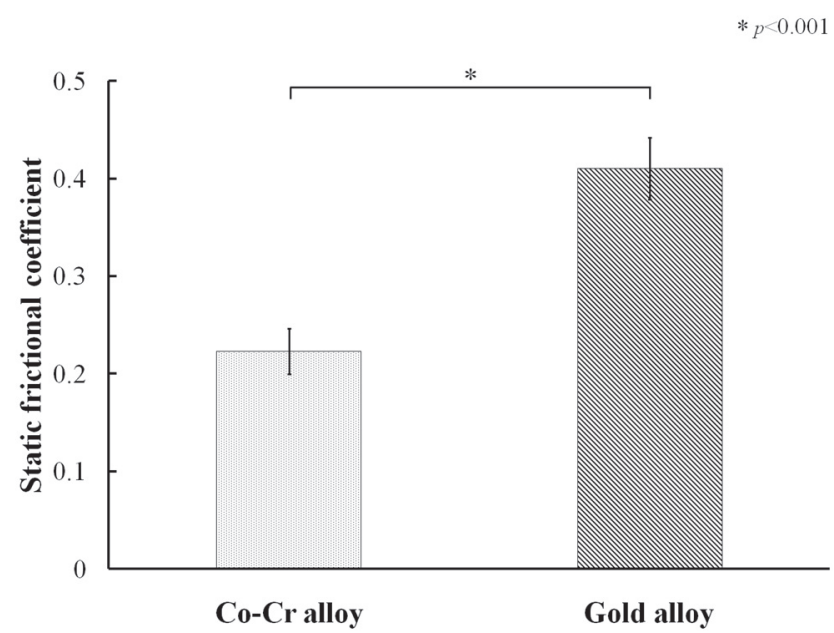

Fig. 3 The SFCs of as-polished Co-Cr alloy and gold alloy. Statistically significant differences were determined by the $t$-test. $p<0.05$ was considered to be statistically significant.

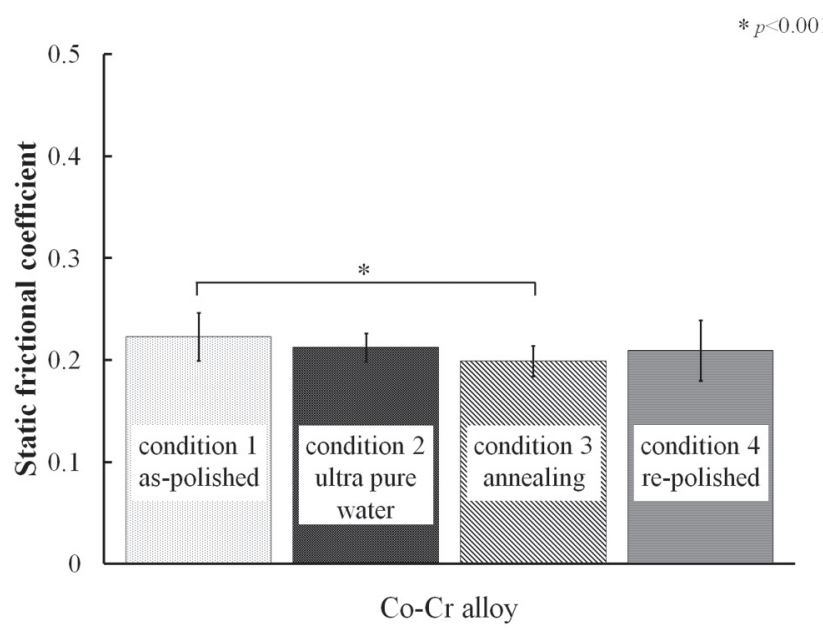

Fig. 4 The SFCs of the Co-Cr alloy after various treatments: Statistically significant differences were determined by One-way ANOVA and Tukey's HSD method. $p<0.05$ was considered to be statistically significant. alloy after various treatments, respectively. Statistically significant differences were evaluated by the One-way ANOVA and Tukey's HSD method. The SFC of the Co$\mathrm{Cr}$ alloy in condition 2 was slightly lower than that in condition 1, although no significant difference was observed $(p=0.186)$. The SFC in condition 3 was lower than that of condition 1 , although no significant difference was observed between conditions 2 and $3(p=0.056)$. The SFC in condition 4 was slightly higher than that in the condition 1 , although no significant difference was observed between conditions 1 to 3 and condition 4.

The SFC of the gold alloy in condition 2 was lower than that in condition 1 . It should be noted that the SFC in condition 3 was significantly lower than that in condition 2. In addition, the SFC in condition 4 was higher than that in condition 3 and was as high as that in condition 1 .

The changes of the SFCs of the Co-Cr alloy were smaller than those of the gold alloy when treatments were conducted in conditions 1 to 4 . Therefore, the SFC of gold alloy is susceptible to treatments in conditions1 to 4 .

A surface analysis of $\mathrm{Co}-\mathrm{Cr}$ alloy and gold alloy

Figure 6 shows the XPS survey spectra obtained from the Co-Cr alloy in the conditions 3 and 4. C, O, N, Co, $\mathrm{Cr}, \mathrm{Mo}, \mathrm{Ga}, \mathrm{W}, \mathrm{Si}, \mathrm{Mn}$, and $\mathrm{S}$ were detected in the Co$\mathrm{Cr}$ alloy with XPS. $\mathrm{C}$ and $\mathrm{N}$ originated from the socalled "contaminant carbon and nitrogen". The elements, other than $\mathrm{O}$ and $\mathrm{S}$, originated from the alloying elements. $\mathrm{O}$ originated from surface oxide and $\mathrm{S}$ may be incorporated into the alloy during the dental casting processes. There was no difference between these specimens.

Figure 7 shows the XPS spectra obtained from the

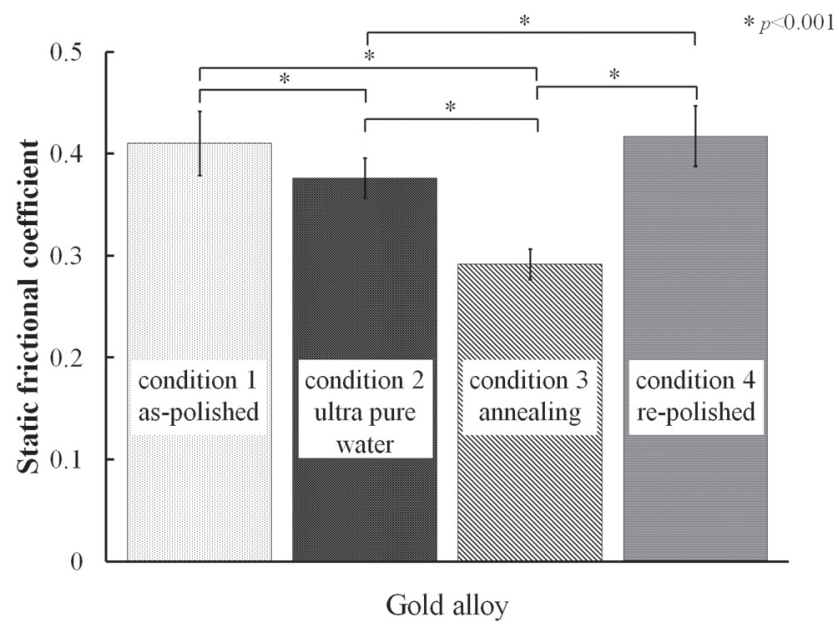

Fig. 5 The SFCs of the gold alloy after various treatments: Statistically significant differences were determined by One-way ANOVA and Tukey's HSD method. $p<0.05$ was considered to be statistically significant. 


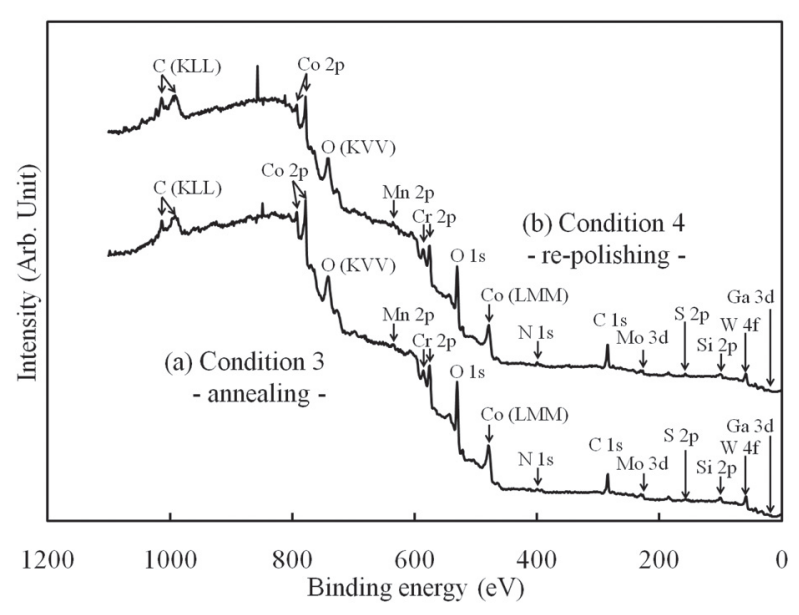

Fig. 6 XPS survey spectra of obtained from the Co-Cr alloy in the (a) condition 3 and (b) condition 4.

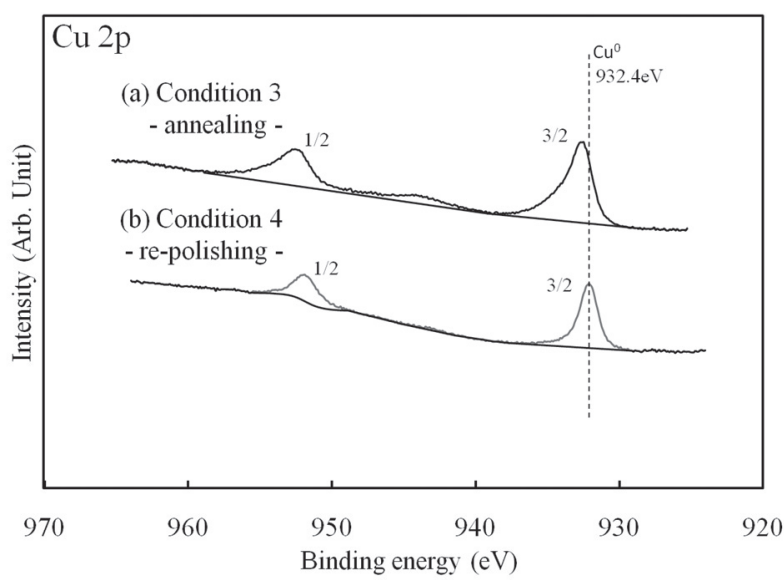

Fig. 8 XPS spectra of $\mathrm{Cu} 2 \mathrm{p}$ electron energy region obtained from the gold alloy in the (a) condition 3 and (b) condition 4.

gold alloy in the conditions 3 and 4. C, O, N, Au, Pt, $\mathrm{Pd}, \mathrm{Ag}, \mathrm{Sn}, \mathrm{Cu}$, and $\mathrm{Zn}$ were detected in the gold alloy with XPS. C and N also originated from the so-called "contaminant carbon and nitrogen". The elements, other than $\mathrm{O}$ were derived from the alloying elements. $O$ originated from surface oxide. The unknown spectrum was observed at $815 \mathrm{eV}$. Figure 8 shows the XPS spectra of $\mathrm{Cu} 2 \mathrm{p}$ obtained from the gold alloy in the conditions 3 and 4 . The $\mathrm{Cu} 2 \mathrm{p}$ spectrum in condition 3 was broadened to a higher binding energy region in comparison to that in condition 4 . This was due to the overlap of some peaks from the valence of $\mathrm{Cu}^{0}, \mathrm{Cu}^{+}$and $\mathrm{Cu}^{2+}$ in that condition 3. The binding energies of $\mathrm{Cu}^{2+}(933.5 \mathrm{eV})^{22)}$ were higher than that of $\mathrm{Cu}^{+}(932.2 \mathrm{eV})^{23)}$ and $\mathrm{Cu}^{0}(932.4 \mathrm{eV})^{21)}$, although it is difficult to separate these peaks. Figure 9 shows the XPS spectra of $\mathrm{Zn} 2 \mathrm{p}$ obtained from the gold alloy in conditions 3 and 4 . Peaks originating from $\mathrm{Zn} 2 \mathrm{p}$ were

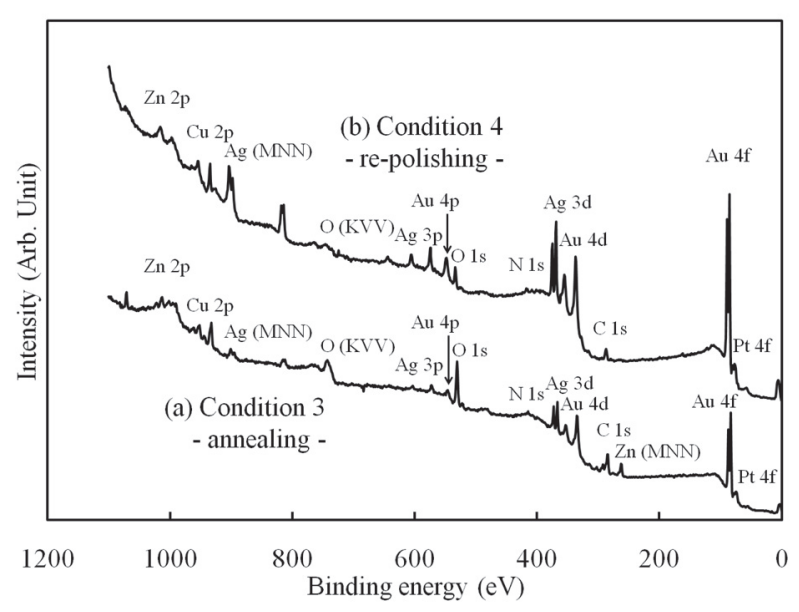

Fig. 7 XPS survey spectra of obtained from the gold alloy in the (a) condition 3 and (b) condition 4 .

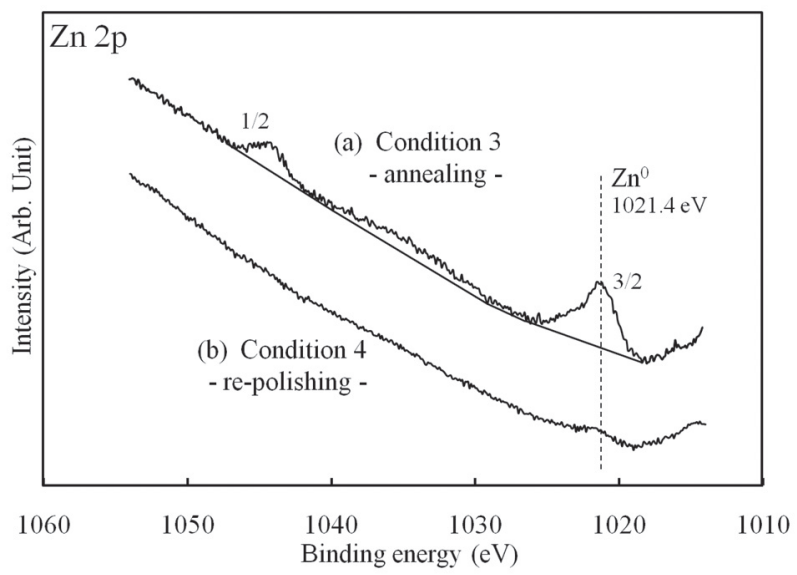

Fig. 9 XPS spectra of $\mathrm{Zn} 2 \mathrm{p}$ electron energy region obtained from the gold alloy in the (a) condition 3 and (b) condition 4 .

detected in condition 3 . The $\mathrm{Zn} 2 \mathrm{p}$ spectrum in condition 3 seemed to be broadened to a higher binding energy. The binding energy of $\mathrm{Zn}^{2+}(1,021.7 \mathrm{eV})^{21)}$ was higher than that of $\mathrm{Zn}^{0}(1,021.4 \mathrm{eV})^{21)}$, although it is difficult to separate these peaks. However, these peaks were not detected in condition 4 .

\section{DISCUSSION}

Effect of treatments on the static frictional coefficient of the Co-Cr alloy and the gold alloy

Amonton's law states that the SFC does not depend on the apparent contact area ${ }^{24)}$. This law works when the surface roughness and the cleanness are in a similar range $^{25)}$. On the other hand, the SFC increases with decreasing the apparent contact area and with increasing circumference length ${ }^{26}$. These suggest that the surface roughness influences the SFC. When the 
plastic deformation occurs at the real contact area, the new surface forms and the strong adhesion occurs between the materials. This contributes to the increase of the SFC. When the elastic deformation occurs at the real contact area, the effect of surface layer is large and the SFC is almost the same value, irrespective of the summation of the real contact area (i.e. roughness). If the surface roughness of the alloys in the condition 2 and 3 increases and the plastic deformation occurs at the real contact area, the SFC should increase owing to their treatments. However, the SFCs of the alloys decreased in the condition from 1 to 3 . In addition, the SFC was almost the same, irrespective of the roughness difference between the condition 1 and 4 . It is considered that the adhesion owing to the plastic deformation at the real contact surface should not occur for both alloys in the tested conditions.

Ludema et al. ${ }^{27)}$ described that when oxygen is present, wear is very much lower, friction is significantly lower and the wear debris is mostly oxide. Thus, all the SFC value obtained in the tests was affected by the presence of oxygen. Generally, an oxide layer, which grows very slowly, forms on the alloy surface of gold alloys. Therefore, adhesion is dominant for the friction of the as-polished gold alloy although the surfaces are contaminated by air. XPS analysis revealed that $\mathrm{Cu}$ and $\mathrm{Zn}$ were oxidized during annealing even at $85^{\circ} \mathrm{C}$, which is close to the polymerization temperature of a denture base resin and the vaporization temperature of ethanol. The gold alloy (type 4) contains $\mathrm{Cu}$ for strengthening and a small amount of $\mathrm{Zn}$ for deoxidization. These elements are easily oxidized during annealing and then the oxide layer containing $\mathrm{Cu}$ and $\mathrm{Zn}$ is formed on the surface. Accordingly, the SFC of the gold alloy decreased by annealing because the layer disturbs the adhesion of metals in the gold alloy.

On the other hand, oxides containing $\mathrm{Cr}_{2} \mathrm{O}_{3}$ and $\mathrm{Co}(\mathrm{OH})_{3}$ form immediately after polishing in $\mathrm{Co}-\mathrm{Cr}$ alloys $^{28)}$. The oxides layer formation of Wirobond 280 is considered to be the same, based on the alloy composition (Table 1). The SFC was thought to be changed because of the dissolution $\mathrm{Co}(\mathrm{OH})_{3}$ in ultra pure water. However, there was no significant difference on the SFC between conditions 1 and 2. The SFC in condition 3 was slightly lower than those in the other conditions. This is presumably due to the stabilization of oxides on the surface during annealing. The SFCs of the Co-Cr alloy in each condition were lower than those of the gold alloy. The stable and thick oxide layer always exists at the surface and disturbs the adhesion of metals. Therefore, the change in the SFC of the Co-Cr alloy may be suppressed in each condition.

Effect of static frictional coefficient on the retentive force of cone crown telescope system

The retentive force in the cone crown telescope system is generated by the residual elastic strain in the outer crown. Figure 10 shows a schematic illustration of the

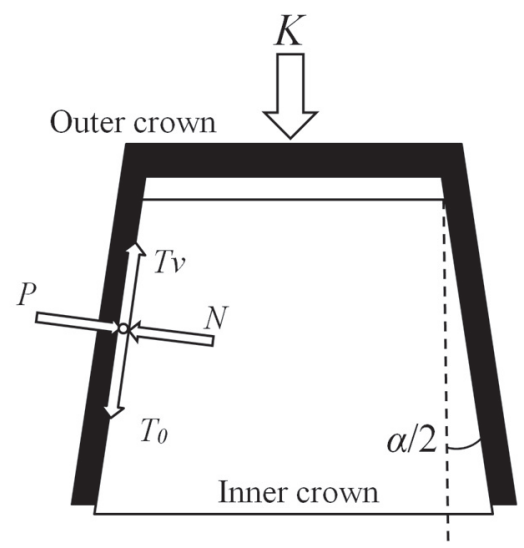

Fig. 10 Schematic drawing of the cone crown telescope system $^{14)}$.

telescope system ${ }^{14)}$. The inner crown is inserted into the outer crown when the occlusal force $(K)$ is applied firmly, and the elastic strain occurs due to the deformation of the outer crown. The elastic strain remains when the occlusal force is removed because of the existence of the inner crown. Therefore, the elastic strain is formed to generate the normal force $(N)$ to the interface between the outer and inner crown. The retentive force $\left(T_{0}\right)$ is expressed using the $\operatorname{SFC}\left(\mu_{0}\right)$;

$$
T_{0}=\mu_{0} N
$$

The normal force $(N)$ is expressed using the cone angle $(\alpha / 2)$;

$$
N=K / \sin (\alpha / 2)
$$

The retentive force $\left(T_{0}\right)$ is expressed using equations 2 and 3;

$$
T_{0}=\mu_{0} K / \sin (\alpha / 2)
$$

Therefore, the retentive force is proportional to the $\mathrm{SFC}^{14)}$. The retentive force is controlled by the SFC and the cone angle from the design of cone crown telescope system. The SFC of the selected alloys should be evaluated before the cone angle is determined in order to obtain the same retentive force as the gold alloy. The SFC of the Co-Cr alloy was lower than that of the gold alloy (Fig. 3). Based on the figure and the experimental results, the cone angle of the $\mathrm{Co}-\mathrm{Cr}$ alloy should be lower than that of the gold alloy. However, the SFC measurements were performed at $22 \pm 1{ }^{\circ} \mathrm{C}$ and the humidity of $69 \pm 4 \%$ in this study. Although it is difficult to determine the exact value of the angle because the SFC depends on the oral circumstance in each patient ${ }^{29)}$, further investigation of the SFC is still needed to discuss on the differences of the retentive force between the alloys in the oral circumstance. 


\section{CONCLUSION}

The SFC of the $\mathrm{Co}-\mathrm{Cr}$ alloy and the gold alloy were evaluated at $22 \pm 1^{\circ} \mathrm{C}$ and the humidity of $69 \pm 4 \%$. The $\mathrm{SFCs}$ of the $\mathrm{Co}-\mathrm{Cr}$ alloy were lower than those of the gold alloy. The SFC of the gold alloy was decreased by annealing at $85^{\circ} \mathrm{C}$ in air and was restored by repolishing, although that of the $\mathrm{Co}-\mathrm{Cr}$ alloy was stable irrespective of the annealing. The XPS analysis revealed that the decrease of SFC of the gold alloy was caused by the formation of an oxide layer at the surface on annealing. The oxide layer of the $\mathrm{Co}-\mathrm{Cr}$ alloy may suppress the change of the SFC in each condition. The cone angle should be considered when the alloy for the cone crown telescope system is changed from the gold alloy.

\section{REFERENCES}

1) Heckmann SM, Heckmann JG, Linke JJ, Hohenberger W, Mombelli A. Implant therapy following liver transplantation: Clinical and microbiological results after 10 years. J Periodontol 2004; 75: 909-913.

2) Heckmann SM, Schrott A, Graef F, Wichmann MG, Weber HP. Mandibular two-implant telescopic overdentures 10year clinical and radiographical results. Clin Oral Implants Res 2004; 15: 560-569.

3) Hoffmann O, Beaumont C, Tatakis DN, Zafiropoulos GG. Telescopic crowns as attachments for implant supported restorations a case series. J Oral Implantol 2006; 32: 291299.

4) Greven B, Luepke M, von Dorsche SH. Telescoping implant prostheses with intraoral luted galvano mesostructures to improve passive fit. J Prosthet Dent 2007; 98: 239-244.

5) Krennmair G, Krainhöfner M, Waldenberger O, Piehslinger E. Dental implants as strategic supplementary abutments for implant-tooth-supported telescopic crown-retained maxillary dentures: A retrospective follow-up study for up to 9 years. Int $\mathrm{J}$ Prosthodont 2007; 20: 617-622.

6) Heckmann SM, Winter W, Meyer M, Weber HP, Wichmann MG. Overdenture attachment selection and the loading of implant and denture-bearing area. Part 1: In vivo verification of stereolithographic model. Clin Oral Implants Res 2008; 12: 612-623.

7) Heckmann SM, Winter W, Meyer M, Weber HP, Wichmann MG. Overdenture attachment selection and the loading of implant and denture-bearing area. Part 2: A methodical study using five types of attachment. Clin Oral Implants Res 2008; 12: 640-647.

8) Eitner S, Schlegel A, Emeka N, Holst S, Will J, Hamel J. Comparing bar and double-crown attachments in implantretained prosthetic reconstruction: a follow-up investigation. Clin Oral Implants Res 2008; 19: 530-537.

9) Igarashi Y, Goto T. Ten-year follow-up study of conical crown-retained dentures. Int J Prosthodont 1997; 10: 149155.

10) Igarashi Y, Ogata A, Kuroiwa A, Wang CH. Stress distribution and abutment tooth mobility of distal-extension removable partial dentures with different retainers: an in vivo study. J Oral Rehabil 1999; 26: 111-116.

11) Langer Y, Langer A. Tooth-supported telescopic prostheses in compromised dentitions: A clinical report. J Prosthet Dent 2000; 84: 129-132.

12) Körber KH. Konuskronen: Das rationelle teleskopsystem einführung in klinik und technik. 5th ed. Heidelberg: Dr. Alfred Hüthig Verlag GmbH; 1988. p. 76.

13) Molin M, Bergman B, Ericson A. A clinical evaluation of conical crown retained dentures. J Prosthet Dent 1993; 70: 251-256.

14) Körber KH. Konuskronen: Das rationelle teleskopsystem einführung in klinik und technik. 5th ed. Heidelberg: Dr. Alfred Hüthig Verlag GmbH; 1988. p. 81-86.

15) Nagata H. Retention in the conic telescopic crown system. The influence of the inner crown form. Shigaku 1989; 77: 571-597.

16) Kido H, Morikawa M, Takeya K, Chigusa R, Toyoda S. Experimental study on retention of the conic telescope crown part I. Effect of the inner crown form. J Jpn Prosthodont Soc 1993; 137: 256-260.

17) Kiyama M, Shiba A. Studies on retentive force of conical telescopic double-crown: part 1. Retentive force of conical telescopic double-crown related to materials and taper angle and height of cone and load. J Jpn Prosthodont Soc 1994; 38: 1252-1264.

18) Güngör MA, Artunç C, Sonugelen M. Parameters affecting retentive force of conus crowns. J Oral Rehabil 2001; 31: 271-277.

19) Koroku H, Tsukasaki H, Marutani Y, Omori H, Shiina Y, Shiba A. Studies on retentive force of conical telescopic double-crown: Retentive force related to thickness and used metal alloys of outer-crown. Showa Shigakkai Zasshi 2004; 24: 160-171.

20) ASTM D1894. Standard test method for static and kinetic coefficients of friction of plastic film and sheeting. Philadelphia: American Society for Testing and Materials; 2008.

21) Moulder JF, Stickle WF, Sobol PE, Bomben KD. Handbook of X-ray photoelectron spectroscopy. 2nd ed. Eden Prairie: Perkin-Elmer Corp; 1992. p. 82-85.

22) Gaarenstroom SW, Winograd N. Initial and final state effects in the ESCA spectra of cadmium and silver oxides. J Chem Phys 1977; 67: 3500-3506.

23) Mcintyre NS, Rummery TE, Cook MG, Owen D. X-ray photoelectron spectroscopic study of the aqueous oxidation of Monel-400. J Electrochem Soc 1976; 123: 1164-1170.

24) Dowson D. History of Tribology. 1st ed. New York: Longman Group Ltd; 1979. p. 210.

25) Rabinowicz E. Friction and wear of materials. 1st ed. New York: John Wiley and Sons Inc; 1965. p. 57.

26) Okada K, Shimizu T. The influence of the apparent area of contacts on friction coeffcient. Tribologist 1992; 37: 306-311.

27) Ludema KC. A review of scuffing and running-in of lubricated surfaces, with asperities and oxides in perspective. Wear 1984; 100: 315-331.

28) Hanawa T, Hiromoto S, Asami K. Characterization of the surface oxide film of a Co-Cr-Mo alloy after being located in quasi-biological environments using XPS. Appl Surf Sci 2001; 183: 68-75.

29) Warr JA. Friction and partial denture retention. J Dent Res 1959; 38: 1066-1074. 